\title{
Interrogating the Rights Discourse on Girls' Education: Neocolonialism, Neoliberalism, and the Post-Beijing Platform for Action
}

\author{
Navtej Purewal
}

\begin{abstract}
This article examines how girls' education since 1995 has emerged as a prominent symbol within the 'rights' discourse coming out of the Beijing Platform for Action. By highlighting the neoliberal and neocolonial processes during this time, particular shifts are traced which show how girls' education has been a symbolic part of the geopolitical canvas in Pakistan and Afghanistan alongside the 'war on terror' and universalisation of education. The article refers to alternative voices which have attempted to disrupt the global narrative of the post-Beijing 'rights' agenda and points to the problems of this in the context of occupations, militarisation, and markets being used simultaneously as strategies for global governance and order.
\end{abstract}

\section{Introduction}

The Fourth World Conference on Women held in Beijing in 1995, presented a moment of optimism around the garnering of a global consensus for the need to address gender inequality. However, it was precisely during this time that new emerging structures and paradigms were being positioned in the new global order soon after the end of the Cold War era in which China, the host of the conference, was also emerging as a new economic superpower. Neoliberalism's triumph meant that discourses on development were now being shaped around concepts of rights, democracy and markets rather than communism and capitalism, as had been professed by Francis Fukuyama (1992). These new demarcations along the contours of the neoliberal global economy's forces of influence meant that democracy, gender and 'rights' became the cornerstones for international policies and platforms.

While the Beijing conference represented an initial optimism around how gender equality could be projected from a position of international consensus, this was quickly quelled by the subsequent period in which the Taliban formed the government in Afghanistan, which began with immediate restrictions on women. After 9/11 a polarised scenario developed globally between the West and the Muslim world in which women's rights, freedoms and mobility became a prominent dimension of the 'war on terror'. In fact, the threat to girls' education under the Taliban has served the purpose of providing a justification for intervention over the past two decades, particularly as the Taliban formed the government of Afghanistan between 1996 and 2001. The liberal West had found an identifiable other in the Taliban in this post-Cold War era and this has now extended to the broader Muslim as well as the developing world under the guise of social and economic development and rights (Toor 2011). The 'war on terror' subsequently played out in Afghanistan and Pakistan has created battlefields in which female education has been used as an ideological weapon.

Viewing girls' education from the 'elsewhere/s... of other-than-Western-democracies', a term coined by Zillah Eisenstein (2004), enables analysis and critique of the dominant discourses on gender which came about after the 1995 Beijing conference. The vantage point of these 'elsewheres' enables a more penetrating reading of how girls' education as a 'right' has become a tool rather than a strategy within the neoliberal economic agenda to proliferate the ideology of the 'free market' while simultaneously sanctioning the neocolonial military intervention 


\section{Part of the reason rigid forms of patriarchy and anti-feminism have developed in our society is because the discourse of women's liberation has historically been used as a justification for intervention by imperial powers.}
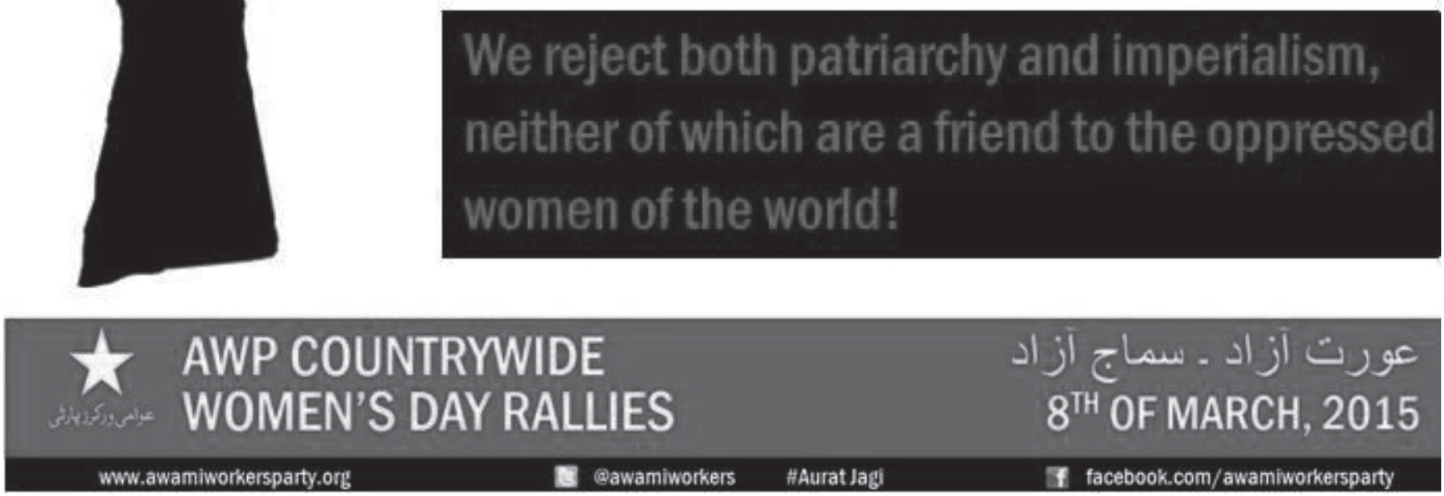

Source www.awamiworkersparty.org. Reproduced with kind permission of Awami Workers Party.

and occupation of the region. This is particularly evident in light of the West's 'war on terror' and its increasingly problematic relation to the Muslim world. International organisations such as the World Bank and UN agencies have not been removed from this scenario. While the World Bank (2011) identifies education as a 'strategic development investment', the positioning of education as a liberal right in the strategies of this era has found a symbol in Malala Yousafzai. Yousafzai was awarded the Nobel Peace Prize in 2014 after being shot in 2012 in Pakistan. Despite edicts from the local Taliban authority, Yousafzai continued to go to school along with other schoolmates in defiance of the edict, and her BBC blog Life Under the Taliban represented a direct opposition to their stance in its mediation through a Western media.

The complexities of the symbol of Malala are highlighted in this prism through which girls' education as a universal, liberal 'right' was in the spotlight at a time when little attention was being paid to the denial of other 'rights', and in a region which the international community had incorporated into its 'war on terror'. The symbol of Malala exists alongside the neocolonial occupation of the region of Afghanistan and Pakistan through the use of US unmanned drones and the broader geopolitics of the 'war on terror', as well as in the spread of neoliberalism through the spread of market principles within public sectors, such as education. The Khyber Pakhtunkhwa province, the province from which Yousafzai originates in Pakistan, as well as Waziristan and the mountainous frontiers of Afghanistan, are a vast terrain of geography and tribal societies who are at the forefront of this ideological battle between neoliberal economics and liberal rights, on the one hand, and a conservative form of Islamism wishing to challenge universal notions of gender, on the other.

Just as the announcement of the withdrawal of North Atlantic Treaty Organization (NATO) forces from Afghanistan was being made in November 2013, the ongoing, sustaining legacy of intervention through the global gender rights discourse was being clearly stated as a longer term strategy. On the eve of the US military withdrawal from Afghanistan, Hillary Clinton, former US Secretary of State, commented: 'We are well aware this is a serious turning point for all the people of Afghanistan, but in particular the hard-fought gains that women and children have been able to enjoy'. She went further in stating that women and girls 'will not go back, they will not be forced back into their homes, denied education and health care, stripped away of their rights to participate in the economic and political systems of their country' (Georgetown University 


\begin{tabular}{llll}
\hline Country & HDI ranking & $\begin{array}{l}\text { Public expenditure on } \\
\text { education (as \% of GNP) }\end{array}$ & $\begin{array}{l}\text { Literacy rate (age 15+) } \\
\text { as \% }\end{array}$ \\
\hline Iran & 94 & 5.2 & 84 \\
Sri Lanka & 99 & 5.4 & 91 \\
Maldives & 100 & 8.3 & 97 \\
India & 128 & 3.3 & 65 \\
Pakistan & 136 & 2.7 & 54 \\
Nepal & 145 & 3.2 & 55 \\
Bangladesh & 140 & 2.8 & 52 \\
\hline
\end{tabular}

2015), with no mention of the local women's and collective voices of opposition to US-led NATO involvement in the region. This reflects a fraught terrain in which neocolonial geopolitics of occupation and intervention have subsequently played out alongside the expansion and penetration of neoliberal market forces. These two processes run in tandem with one another, which is also knowingly perceived and articulated by critical voices and movements who recognise how women and the post-1995 gender discourse have not only served both agendas of neoliberalism and neocolonialism but also the implicit patriarchal underpinnings of both. An example of this can be found in a leaflet publicising an International Women's Day rally in March 2015 held in Islamabad by the Awami Workers' Party (AWP) (Figure 1).

\section{Complementary strategies: Beijing Platform and Education for All (EFA)}

Running alongside the rights discourse around gender, which emerged following the Beijing conference in 1995, the universalisation of the education agenda became a complementary strategy within the new global order. EFA was the global agenda emerging out of the UN world conferences in Jomtien, Thailand in 1990 and Dakar, Senegal in 2000 where a target for eliminating gender disparities in educational access and literacy, particularly for girls and women, was set for 2015 (Mundy 2006; UNESCO 2000). The EFA agenda forms part, in addition to the Beijing Platform for Action (BPfA), of the social safety net approach which embodies a critique of the purely economic market approaches of the Washington Consensus, including the notion of social responsibility by states and stakeholders, public and private (Stiglitz 2008).
Under the UN's EFA platform and the Millennium Development Goals (MDGs) there is clear encouragement of private sector involvement in education in situations where the state seems unable to deliver. This is grounded at the ideological level in which states must accept responsibility for providing universal education and in promoting girls' education more specifically either solely through, or in partnership with, private interests. Pakistan is a prime market for education to flourish within such private partnership arrangements. Literacy rates in Pakistan are particularly low in comparison to other South Asian countries, while public expenditure is the lowest in the region (Table 1).

In an indicator given by the World Economic Forum's 2014 Global Gender Gap (World Economic Forum 2014), Pakistan, ranked 141, is second to the bottom only above Yemen, ranked 142, in terms of gender parity, with no data being available for Afghanistan.

With its stated aim of establishing a global framework on 'equality, development and peace', there is much scope to look more critically at how the BPfA has been situated within the subsequent geopolitics of the expansion of global neoliberal economic reforms requiring neocolonial intervention, a purpose which girls' education has served. Thus, the military requirements of neocolonialism and the economic authority of the neoliberal market economy has tactically utilised girls' education as a means of asserting moral and ideological authority.

In projecting the mission and understanding that 'equality between women and men is a matter of human rights and a condition for social justice...', 
the BPfA's strategic objectives were hinged on a notion of global rights framed within a broadly stated concept of equality. While on the surface this appears a straightforward set of goals, the perception and adoption of the rights agenda in different countries, like the 1979 Convention on the Elimination of All Forms of Discrimination against Women (CEDAW) was that of one of Western conceptions of gender (Baden and Goetz 1997).

Beyond the criticisms that the BPfA reflected a Western-centric, universalising women's rights agenda, it was also perceived as a tool for the international community's interests in penetrating economies and societies through the target-driven approach showing symbolic commitment to uplift girls and women through education and other policy interventions, rather than addressing structural dimensions of women and girls' discrimination (Croll 2006). Thus, as the AWP leaflet poignantly stated on the eve of International Women's Day in 2015 as cited above, the 'rights' discourse has implicit ties to how justifications for policy interventions have been made.

\section{Neocolonial and neoliberal undercurrents: the girls' education policy agenda in Pakistan and Afghanistan}

Of the strategic objectives and actions from the BPfA, the girls' education policy agenda has emerged out of two specific areas:

- education and training of women;

the girl-child.

The synthesis of these two areas in the establishment of girls' education focuses on how the girl-child is 'discriminated against from the earliest stages of life, through her childhood and into adulthood' and inserts education '[as] a human right and an essential tool for achieving the goals of equality, development and peace'. Out of this synthesis, we can see the positioning of the girl-child as the object of policy focus.

Female education was one of the first issues to be highlighted when the Taliban formed the RabbaniMassoud government in 1992 and then subsequently governed between 1996 and 2001. The various bans and restrictions had an immediate impact on women and girls' access to the public sphere. In particular, the requirement of all women and girls to be accompanied by a mahram (close male relative) as well as the ban on women studying in schools or universities, led to an immediate halt on formal female education and participation in public life. ${ }^{1}$ While the Taliban used the ban on female education as a tool to establish authority and sovereignty in Afghanistan by showing an alternative, oppositional gender paradigm to that embodied in the BPfA, the mounting gender equality lobby internationally through mainstreaming, and its definitions and conceptions of equality no doubt provided a direct target for the Taliban's ideological message. Indeed, the restrictions on women provided one of the most significant justifications for Western intervention in the region in highlighting an identifiable other in the Taliban in the post-Cold War era. The Taliban ban on girls' education presented a moral justification for US-led NATO military intervention and occupation for nearly two decades. Thus, we can see that one of the unforeseen outcomes of the BPfA has been a backlash and resistance to universal gender goals.

In order to consider how this resistance to the BPfA has been formulated, it is also essential to understand how the internal and external impositions and occupations of Afghanistan have been understood by women. RAWA (the Revolutionary Association of the Women of Afghanistan) made clear distinctions between the 'Jehadi' forces which created the first 1992 government which resulted in force and sexual violence and the subsequent Taliban government which enforced physical restrictions on dress, behaviour and mobility:

We consider Taliban more treacherous and ignorant than Jehadis. According to our people, 'Jehadis were killing us with guns and swords but Taliban are killing us with cotton.'2

However, religious fundamentalist interpretations of gender do not provide a sufficient explanation for the politicisation of the symbol of girls' education. The backdrop to restrictions on girls' education in Afghanistan and Pakistan is that of gender and culture - not necessarily owned by Taliban interpretations of religion but embedded in regional cultures which deem girls' education a risk or threat to family or other collective interests around kinship. Many girls in Pakistan, in areas not within reach of Taliban influence, face restrictions of going to school from parents whose decisions are often shaped by considerations around the household labour force, respectability, and whether or not educating one's daughter will bring returns to the family which outweigh the loss incurred by her absence during the school day (Purewal and Hashmi 2014). 
The ideological positioning of girls' education has run alongside the neocolonial contexts of Afghanistan and Pakistan in which the global 'war on terror' has escalated and the symbol of the girl-child and hence girls' education has become a parallel mission of the global community. However, the economic interests in maintaining and establishing stable markets highlights the neoliberal context of girls' education in the region. While Malala Yousafzai has continued to highlight the broader context of drone attacks which have killed an estimated 3,000 civilians in Pakistan to date, the global consensus on gender equality and girls' education has continued to utilise her as a symbol for the liberal project of gender equality. Her symbol is fraught and contested by simultaneously being evoked in the 'war on terror' as evidence of the need for intervention while also selectively ignoring articulations in support of socialism and an end to drone attacks which have been publicly voiced by Yousafzai.

The ownership of the mantra of girls' education has perhaps been most explicitly occupied in the symbol of Malala Yousafzai by the international policy establishment which, on the one hand, is aligned to the principles of the BPfA, while on the other hand, comprises the decision-making which, in part, reflects the NATO alliance. While there is a distinction to be made between the UN (and its various bodies) and NATO, the lines are often blurred in terms of the overlapping discourses of justification for intervention and liberal 'rights'. To those on the receiving end of international declarations and policies, this can be most starkly observed in RAWA's outspoken position and understanding of the internal and external dynamics of gender occupation by both Taliban and NATO forces which highlights an important vantage point through which to see how the girls' education policy discourse is being challenged:

Let us drive away the US and NATO occupiers with our unity! (2014)

Afghan women burn in the fire of the oppression of the occupiers and fundamentalists $(2013)^{4}$

The likening of 'occupiers' and 'fundamentalists' shows an internal feminist response that is aligned to neither NATO's interventions nor to the religious conservativism seeking to establish state Islamism in Afghanistan and Pakistan. Both are synonymised with oppression, according to RAWA and the AWP, which shows how women's/progressive organisations in the region view gender policies from above in light of global interventions and localised responses.

\section{Conclusion}

Reflecting on the Beijing conference with 20 years of hindsight provides an opportunity to look critically and retrospectively upon the profound processes that were at play in 1995. The end of the Cold War, the emergence of China as a global economic power, the post-Washington Consensus, and the neocolonial expressions of this time in the occupations of Iraq, Afghanistan and the 'war on terror' made this period a tumultuous one for geopolitics, not least in relation to gender. By situating the BPfA at the brink of wider geopolitical shifts that were taking place in the mid-1990s we can also begin to understand how gender, 'rights' and girls' education more specifically have come to occupy such a symbolic role at the international level. This, as has been argued here, is a result of the ascendance of neoliberal economic policies and their necessarily accompanying neocolonial ideology.

The neoliberal and neocolonial foundations of the contemporary geopolitical context which privileges the West as universal as reflective of the standards of democracy, 'rights' and liberal values denies radical pluralism and agency to the non-West (Goldberg 1993). Rather than viewing the Beijing conference and its ensuing outcomes as a neutral space and discourse, it is important to examine and understand how the BPfA has been perceived and responded to not only at supranational and national governmental levels, but also in the 'elsewhere/s... of otherthan-Western democracies' (Eisenstein 2004), local contexts, as well as in the voices of groups and movements operating within less mainstreamed discursive spaces. I would go further in arguing that while the BPfA represented a triumph for women's 'rights' at the supranational level, it also represented and continues to represent an imperious occupation of the language of 'rights' which is distant from the conceptualisations of rights by groups and autonomous movements in voicing feminist politics in relation to patriarchies of control, militarisation, and other forms of occupation.

The discourse on gender inequality which found much resonance in the BPfA with its indicators of gender parity and human development have become established as the gauge by which to assess targets for achieving gender equality within a liberal social policy framework. This liberal discourse on rights does not represent the sentiments of all women and, to the contrary, has had an alienating effect on groups and movements mobilising for rights on different terms, often challenging the universalisms of the West, global institutions, and local and 
state patriarchal forces. The examples highlighted earlier of statements by AWP and RAWA articulate critiques which are both aware and disparaging of these forces.

Gender mainstreaming, which became one of the key strategies of the BPfA, resulted in more concerted attention to institutional and chronic dimensions of gender inequality across a number of different indicators, such as those given in Table 1. From our vantage point of the 'elsewhere/s of other-than-Western-democracies', however, gender mainstreaming is not a policy strategy removed from the broader post-Washington neoliberal context. It not only runs alongside but exists within the same discursive terrain of development, progress, equality and rights.

Left and/or feminist groups and movements, such as the AWP and RAWA, meanwhile are mobilising against both neocolonial and neoliberal interventions as well as Islamist forces vying for moral and political authority, while gender mainstreaming as a policy instrument as part of the UN system represents the conventions of the institutional arrangements for gender provision resulting from the BPfA. Those on the receiving end of strategies for gender equality are also on the receiving end of the 'war on terror', religious conservatism, and the repercussions of both on women. The increasing pressures upon families and households to be productive units alongside the demise of welfare principles has amplified the negative connotations of the language of equality and anti-discrimination imbibed in the BPfA. Any assessment of Beijing+20 in respect to the regions of Afghanistan and Pakistan would be incomplete without reflecting this fraught terrain.

This reflective lens does, however, provide some possibilities for looking towards the future by issuing a cautionary reminder of the ideological nature of the remit within which gender policies and strategies operate. The tools of tracking and monitoring gender disaggregated data, such as the World Economic Forum's Gender Gap, have to date been largely utilised as part of the post-Washington Consensus in presenting action-oriented and resultsdriven targets and, in the process, disguising the use of such data sets in promoting the decline of notions of collectivity, social welfare and public ownership in favour of neoliberal individualism, 'rights' and growth. There may, however, be methodological possibilities yet to be explored which can also look to the quantifiable gender indicators but to apply them in other innovative ways in achieving and projecting new, autonomous and organically feminist interpretations of gender data for action.

The BPfA and its subsequent developments do not necessarily have to represent a singularising, proselytising force. The principles and declarations meant to address discrimination could be worked in less totalising terms and in ways which allow for more complex engagements with the economic and political challenges faced by women in places where women's agency and visibility are being struggled for and asserted every day, without the propaganda of globalised symbols like Malala Yousafzai or spokeswomen aligned to Western state power like Hillary Clinton or Laura Bush. There is a ubiquitous accessibility to critical and credible voices through the burgeoning social and other media to non-co-opted women's voices (and not just those that appear evident through the funding channels of development agencies and non-governmental organisations (NGOs)). These voices, like RAWA and AWP, are addressing their local and broader contexts and offering insightful and engaged contributions while being questioning of the status quo and challenging blanket policies and strategies when applied as part of the broader global agendas. There is both the space and demand for more engagement outside of the supranational and national structures of the neoliberal order. However, the side-lining of anti-capitalist positions has excluded such articulations from mainstream discourses.

If the international community were interested in promoting gender equality and girls' education in a more meaningful way and not merely as an accompaniment to the neoliberal and neocolonial strategies of control in Pakistan and Afghanistan, then the challenging voices of organisations such as RAWA and AWP would not appear so marginal to the dominant discourse on 'rights' that has ascended. The twentieth anniversary of the BPfA is indeed a moment of reflection, but also a moment of opportunity to act on the hindsight of the shifts and ruptures that have transpired globally since 1995 . 


\section{Notes}

1 Boko Haram (translation 'Western education is forbidden') in northern Nigeria presents another example of how female education has become a symbol of anti-Western sentiments politicised by its connections with the global order and asserts to establish sovereignty in northern Nigeria through a direct, armed challenge to girls' education.

\section{References}

Baden, S. and Goetz, A. (1997) 'Who Needs [Sex] When You Can Have Gender? Conflicting Discourses on Gender at Beijing', Feminist Review 56: 3-25

Croll, Elisabeth (2006) 'From the "Girl Child" to Girls' Rights', Third World Quarterly 27.7: 1285-97

Eisenstein, Z. (2004) Against Empire: Feminisms, Racism, and the West, New Delhi: Kali for Women

Fukuyama, F. (1992) The End of History and the Last Man, New York NY: Penguin

Georgetown University (2015) 'Sec. Kerry, Hillary Clinton, Laura Bush Advocate for Afghan Women's "Hard-Fought Gains", www.georgetown.edu/news/afghan-womensymposium.html (accessed 9 May 2015)

Goldberg, D.T. (1993) Racist Culture, Cambridge: Blackwell

Mundy, K. (2006) 'Education for All and the New Development Compact', in J. Zajda, S. Majhanovich and V. Rust (eds), Education and Social fustice, The Netherlands: Springer

Purewal, N. and Hashmi, N. (2014) 'Between Returns and Respectability: Parental Attitudes
2 RAWA, www.rawa.org.

3 RAWA, announcement on the 13th anniversary of the US invasion, 7 October 2014.

4 RAWA, International Women's Day, 8 March 2013.

towards Girls' Education in Rural Pakistan', British Fournal of the Sociology of Education

Stiglitz, Joseph (2008) 'Is there a Post-Washington Consensus Consensus', in N. Serra and J.E. Stiglitz (eds), The Washington Consensus Reconsidered: Towards a New Global Governance, Oxford: Oxford University Press

Toor, S. (2011) The State of Islam: Culture and Cold War Politics in Pakistan, London: Pluto Press

UNESCO (2010) Why Gender Equality in Basic Education in Pakistan?, Islamabad: UNESCO

UNESCO (2000) 'The Dakar Framework for Action: Education for All: Meeting our Collective Commitments', UNESCO, http://unesdoc. unesco.org/images/0012/001211/121147e.pdf (accessed 18 May 2015)

World Bank (2011) Learning for All: Investing in People's Knowledge and Skills to Promote Development: World Bank Education Strategy 2020, Washington DC: International Bank for Reconstruction and Development/World Bank

World Economic Forum (2014) The Global Gender Gap Report 2014, http://reports.weforum.org/globalgender-gap-report-2014 (accessed 18 May 2015) 